\title{
Bladder Outlet Obstruction Secondary to a Brunn's Cyst
}

\author{
Gwen M. Grimsby ${ }^{\mathrm{a}} \quad$ Mark D. Tyson ${ }^{\mathrm{a}} \quad$ Bernard Salevitz $^{\mathrm{a}} \quad$ Maxwell L. Smith $^{\mathrm{b}} \quad$ Erik P. Castle $^{\mathrm{a}}$ \\ Department of aUrology, 'baboratory Medicine and Pathology, Mayo Clinic, Phoenix, Ariz., USA
}

\section{Key Words}

Obstruction $\cdot$ Prostate $\cdot$ Brunn's cyst

\begin{abstract}
Introduction: Bladder outlet obstruction in younger men is often secondary to urethral stricture disease. In the older population it is often a result of benign prostatic hypertrophy. Materials and Methods: We describe the diagnosis, treatment, and outcome of a rare case of a Brunn's cyst causing bladder outlet obstruction in a 43-year-old male who was evaluated for obstructive urinary complaints. Results: Ultrasound and cystoscopy revealed a cystic lesion at the bladder neck. Transurethral unroofing of the cyst resulted in resolution of the obstructive symptoms and resumption of normal voiding. Final pathology revealed a cystic structure with predominately denuded urothelium with multiple submucosal cystically dilated von Brunn's nests, most consistent with a Brunn's cyst. A search of the literate reveals only one similar case. Conclusions: We present the rare case of a Brunn's cyst causing bladder outlet obstruction in a young man.
\end{abstract}

Copyright $\odot 2012$ S. Karger AG, Basel

\section{Case Report}

A 43-year-old male presented to our clinic complaining of an acute onset of a decreased force of his urinary stream 3 weeks prior to presentation. The patient also noted associated urinary urgency, frequency, intermittency and hesitancy. AUA symptom score was 21 with a bother score of 5 . A trial of empiric antibiotics did not alter his symptoms.

Past medical history was pertinent for sleep apnea, migraine headaches and repair of deviated septum. His only medications included as needed ibuprofen. He used no tobacco, alcohol or recreational drugs. Rectal exam revealed a boggy prostate and he was presumed to have prostatitis and placed on tamulosin and ciprofloxacin for 30 days. Urine and prostatic cultures were negative for infection. The patient was seen 6 weeks later with unchanged symptoms.

\section{Diagnosis}

Uroflow at 6 weeks revealed a voided volume of $253 \mathrm{ml}$, peak flow of $5 \mathrm{ml} / \mathrm{s}$, average flow of $4 \mathrm{ml} / \mathrm{s}$ and a residual of $292 \mathrm{ml}$. It took him $56 \mathrm{~s}$ to complete his void. Renal and bladder ultrasound revealed a cystic structure in the bladder (fig. 1). Cystoscopic examination subsequently revealed a normal anterior and prostatic urethra. Upon retro-flexion, a cystic structure was noted at the 12 o'clock position pushing down like a ball valve at the bladder neck (fig. 2). It was felt that this cystic structure seen on bladder ultrasound and cystoscopy was the cause of the patient's obstructive urinary complaints and thus treatment was warranted.

\section{Treatment and Management}

The patient was taken to the operating room for a transurethral unroofing and resection of the cystic lesion. Final pathologic analysis revealed a large cystic structure with predominately denuded urothelium with multiple submucosal cystically dilated von Brunn's nests, most consistent with a Brunn's cyst (fig. 3). The

\section{KARGER}

Fax +4161306 1234

E-Mail karger@karger.ch

www.karger.com
(C) 2012 S. Karger AG, Basel

1015-9770/12/0061-0050\$26.00/0

Accessible online at:

www.karger.com/cur
Gwen M. Grimsby, MD

Department of Urology, Mayo Clinic

5777 East Mayo Blvd

Phoenix, AZ 85050 (USA)

Tel. +1 480301 3162, Fax +1 480342 2799, E-Mail Grimsby.Gwen@mayo.edu 


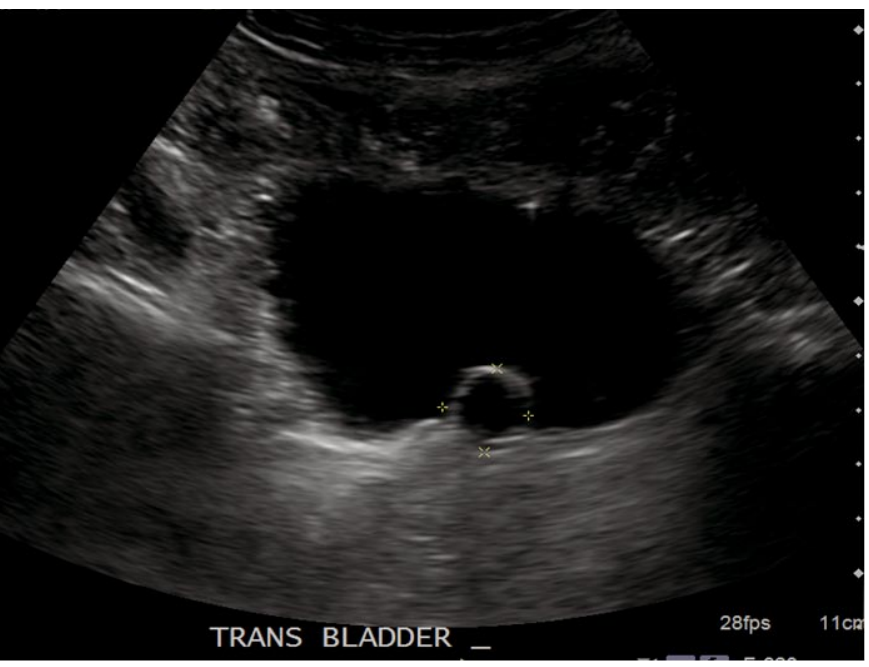

Fig. 1. Bladder ultrasound revealing cystic lesion.

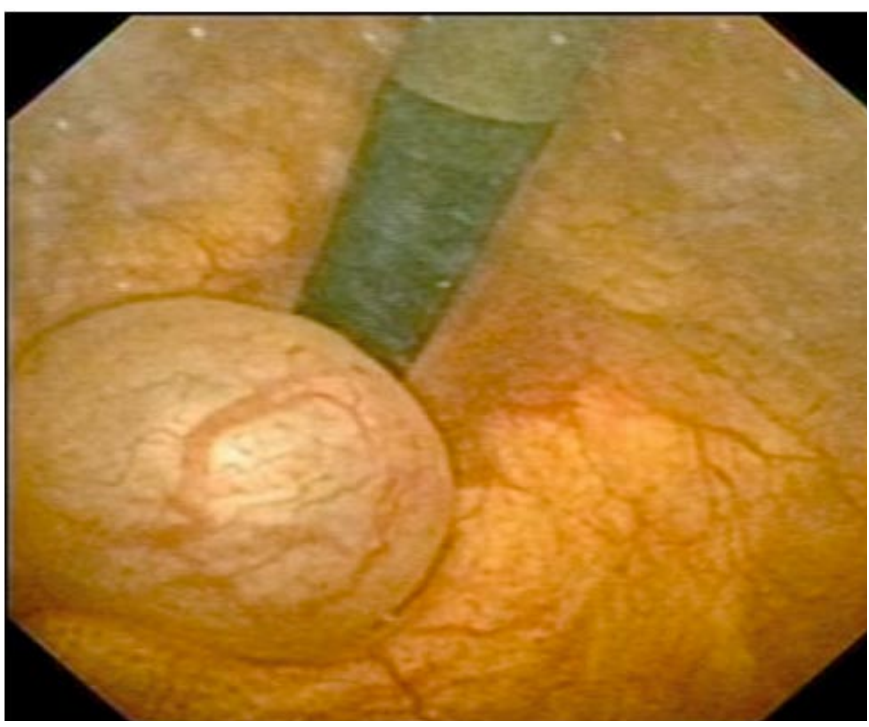

Fig. 2. Cystoscopic view of cystic lesion.

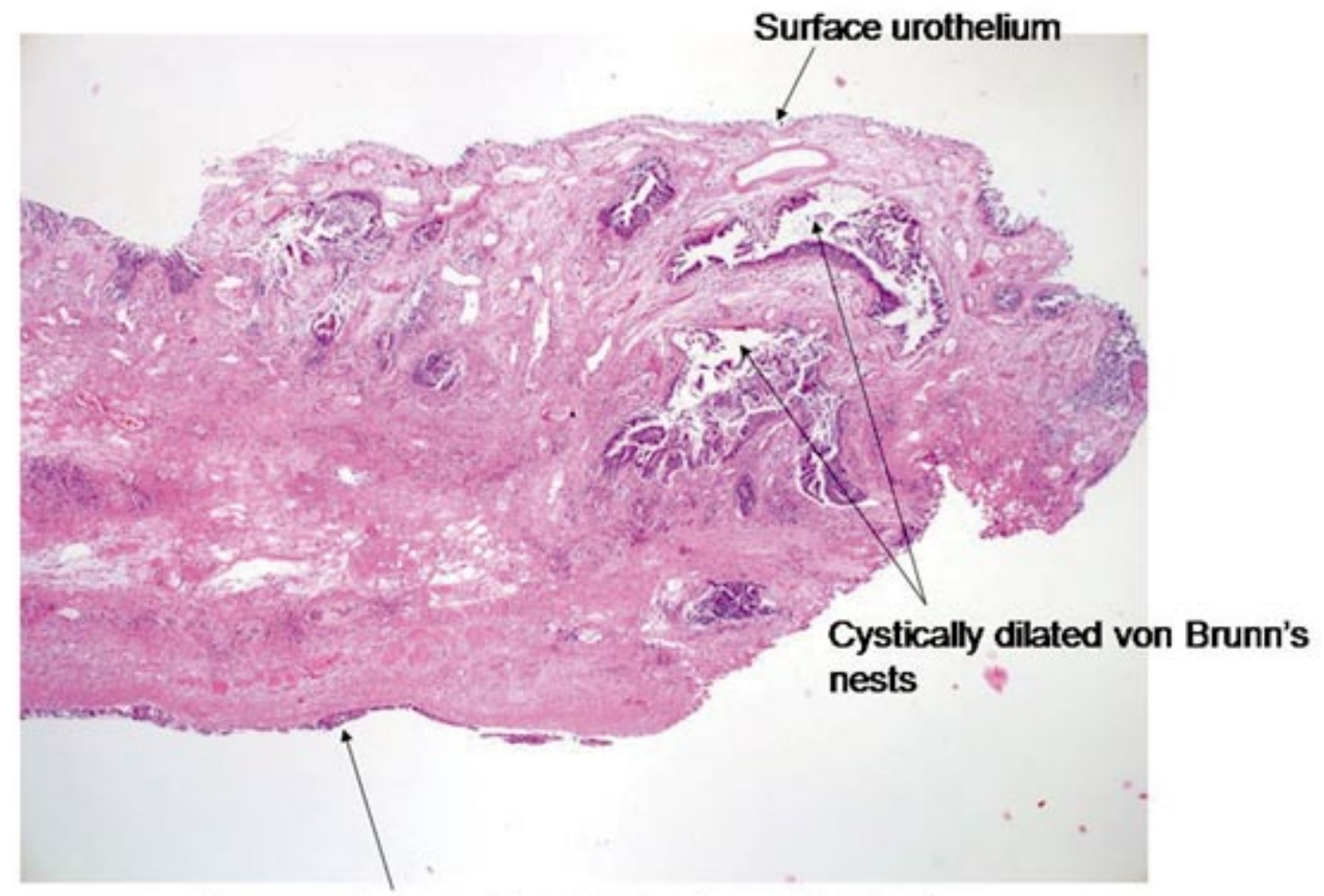

\section{Large submucosal cystic structure with focal islands of urothelium consistent with Brunn's cyst}

Fig. 3. Final pathology revealing a Brunn's cyst. 
patient was seen in the office 3 weeks after the procedure and was able to void to completion. His obstructive urinary tract symptoms were resolved and post void residual was $0 \mathrm{ml}$.

\section{Discussion}

\section{Background of the Diagnosis}

Mucosal cysts such as Brunn's cysts are considered to originate from Brunn's nests which are thought to be the result of pinching off of epithelial nests from urothelial buds [1]. Wiener et al. [2] found that Brunn's nests were present in $89 \%$ of specimens that contained Brunn's cysts and cystitis cystica. In their report, no cysts involved the bladder neck but many were noted to involve the ureter [2]. Franco et al. [3] hypothesized that Brunn's cysts may be congenital in origin.

\section{Differential Diagnosis}

There are cases noted in the literature of infra-vesical obstruction due to cystic lesions of the prostate [4-6]. Most prostatic cysts are located in the medial portion of the prostate and originate from posterior structures such as the utricle, ejaculatory duct, or from an intra-urethral ectopic ureter [4]. Many are asymptomatic or may present with symptoms of bladder outlet obstruction as in our patient or with difficultly in catheterization [7]. Previous publications have reported good outcomes with transurethral resection of cystic lesions, as was performed in our patient [4-6].

The cystic lesion our patient had, however, was not in the prostate but rather at the bladder neck. The literature reveals only one case similar to ours, reported in 1988, a 29-year-old male was noted to have progressive obstructive lower urinary tract symptoms [3]. On cystoscopic retro-flexion a large cystic mass was noted between 7 and 11 o'clock. The patient was taken to the operating room for transurethral drainage resulting in resolution of his symptoms [3].

Final pathology in the previous case included Brunn's nests and a cystic structure with attenuated urothelium consistent with a Brunn's cyst [3]. This was consistent with the pathology in our patient of benign urothelium with multiple submucosal cystically dilated von Brunn's nests and a large cystic structure with predominately denuded epithelium. Reports in the literature of prostatic cysts report pathology composed of multiple layers of squamous cells, columnar epithelium, or non-urothelial epithelium [7-9]. We thus feel that not only the location but the pathology of our lesion makes it unique and distinct entity from prostatic cysts reported in the literature.

\section{Conclusion}

A cystic lesion containing Brunn's nests and denuded urothelium consistent with a Brunn's cyst caused bladder outlet obstruction in our patient. Transurethral unroofing of the cyst resulted in resolution of the obstructed symptoms and resumption of normal voiding. This unique lesion should be considered in the differential diagnosis in a patient with bladder outlet obstruction and a cystic lesion at the bladder neck.

\section{References}

1 Goldstein AM, Fauer RB, Chinn M, Kaempf MJ: New concepts on formation of Brunn's nests and cysts in urinary tract mucosa. Urology 1978;11:513-517.

-2 Wiener DP, Koss LG, Sablay B, Freed SZ: The prevalence and significance of Brunn's nest, cystitis cystica and squamous metaplasia in normal bladders. J Urol 1979;122:317321.

-3 Franco I, Eshghi M, Schutte H, Srinivasan K, Addonizio JC: Bladder neck obstruction secondary to Brunn's cyst. J Urol 1988;139:126127.
4 Chang SG, Hwang IC, Lee JH, Park YK, Lim JW: Intravesical obstruction due to a benign intraurethral prostatic cyst. J Korean Med Sci 2003; 18:125-126.

$5 \mathrm{Ng}$ KJ, Milroy EJ, Rickards D: Intraprostatic cyst - a cause of bladder outflow obstruction. J R Soc Med 1996;89:708-709.

6 Tambo M, Okegawa T, Nutahara K, Higashihara E: Prostatic cyst arising around the bladder neck - cause of bladder outlet obstruction: two case reports. Hinyokika Kiyo 2007;53: 401-404.
7 Kondo A, Kamihira O, Matsuura O: A myleodysplastic male patient presenting with difficult catheterization as a result of a prostatic utricle cyst. Int J Urol 2009;16;978-979.

8 Shirakawa H, Kozakai N, Sugiura H, Hara S: Prostatic retention cyst around the bladder neck: a case report. Hinyokika Kiyo 2009;55: 583-586.

$\checkmark 9$ Nayyar R, Dogra PN: Anteriorly placed midline intraprostatic cyst. J Endourol 2009;23: 595-597. 